\title{
Presence of transmural posterolateral scar by LGE $M R I$ is associated with non-response to CRT
}

\author{
Leslie Chan ${ }^{1}$, Jonathan Suever ${ }^{2}$, Brandon Fornwalt ${ }^{1}$, Stephanie Clement-Guinaudeau', Antonello D'Andrea ${ }^{3}$, \\ Luca Del Viscovo ${ }^{3}$, Frits Prinzen ${ }^{4}$, Frank Bracke ${ }^{5}$, Angel Leon ${ }^{1}$, David Delurgio ${ }^{1}$, Michael Lloyd ${ }^{1}$, John Oshinski ${ }^{*}$ \\ From 2011 SCMR/Euro CMR Joint Scientific Sessions \\ Nice, France. 3-6 February 2011
}

\section{Objective}

Evaluate the effect of myocardial scar burden, scar location, and scar transmurality on response to cardiac resynchronization therapy (CRT)

\section{Background}

Several recent single center studies have used late Gadolinium enhancement (LGE) MRI to predict which patients would likely not respond to cardiac resynchronization therapy (CRT). Results from these studies have varied on the importance of scar location, transmurality, and burden on response to CRT. We analyzed cardiac MRI in patients undergoing CRT from 4 centers (two in Europe and two in the US), and hypothesized that the presence of transmural scar in the posterolateral wall (the most frequent site of left ventricular lead placement in CRT) would preclude positive response to CRT.

\section{Methods}

Cardiac MRI was performed according to standard methods and included at a minimum, cine imaging and LGE imaging using a Gadolinium-based contrast agent. All patients met current criteria for CRT (LVEF $<35 \%$, QRS $>120$ msec). Sixty (60) patients from 4 centers were analyzed, and any patient with infarct enhancement on LGE by visual inspection was processed into an LGE bullseye map following AHA guidelines. Total scar burden (as \% of LV mass) as well as the presence of transmural scar in the posterolateral or septal segments were assessed. $48 \%$ of patients (29/60) patients had LGE and $59 \%$ of those $(17 / 29)$ had transmural scar in at least one AHA segment. Positive response was assessed at 6 months both by clinical (increase of $20 \%$ in 6 minute hall walk distance) and echocardiographic (reduction of LVESV by 15\%) parameters.

\section{Results}

None of the patients with transmural posterolateral scar responded by clinical criteria, and only one patient with posterolateral scar responded by echocardiographic criteria (negative predictive value, NPV $=90 \%$ ). The negative predictive value for the presence of transmural septal scar or total scar burden $>15 \%$ were lower $(\mathrm{NPV}=64-67 \%)$.

\section{Conclusions}

The presence of transmural posterolateral scar by LGE is predictive of non-response to CRT.

\section{Author details}

${ }^{1}$ Emory University School of Medicine, Atlanta, GA, USA. ${ }^{2}$ Georgia Institute of Technology / Emory University, Atlanta, GA, USA. ${ }^{3}$ Second University of

Naples, Naples, Italy. ${ }^{4}$ Maastricht University, Maastricht, Netherlands.

${ }^{5}$ Catharina Hospital Eindhoven, Eindhoven, Netherlands.

Published: 2 February 2011

doi:10.1186/1532-429X-13-S1-P256

Cite this article as: Chan et al:: Presence of transmural posterolateral scar by LGE MRI is associated with non-response to CRT. Journal of Cardiovascular Magnetic Resonance 2011 13(Suppl 1):P256.

${ }^{1}$ Emory University School of Medicine, Atlanta, GA, USA

Full list of author information is available at the end of the article

C 2011 Oshinski et al; licensee BioMed Central Ltd. This is an open access article distributed under the terms of the Creative Commons 